\title{
Extent and severity of atherosclerotic involvement of the aortic valve and root in familial hypercholesterolaemia
}

\author{
L Rallidis, R P Naoumova, G R Thompson, P Nihoyannopoulos
}

\begin{abstract}
Objective-To compare the frequency of valvar and supravalvar aortic stenosis in homozygous and heterozygous familial hypercholesterolaemia (FH).

Design-Analysis of life time cholesterol exposure and prevalence of aortic atherosclerosis in 84 consecutive cases attending a lipid clinic.

Setting-A tertiary referral centre in London.

Patients-Outpatients with FH (six homozygous, 78 heterozygous).

Interventions-Maintenance of lipid lowering treatment.

Main outcome measures-Calculated cholesterol $\times$ years score (CYS) and echocardiographic measurement of aortic root diameter, aortic valve thickness, and transaortic gradient.
\end{abstract}

Results-Four homozygotes with a mean (SD) CYS of 387 (124) $\mathrm{mmol} / 1 \times$ years had severe aortic stenosis (treatment started after seven years of age), whereas the other two had echocardiographic evidence of supravalvar thickening but no aortic valve stenosis (treatment started before three years of age). On multivariate analysis, mean transaortic gradient correlated significantly with CYS (mean $=523$ (175) $\mathbf{m m o l} / 1 \times$ years) in heterozygotes $(p=0.0001)$, but only two had severe aortic valve and root involvement.

Conclusions-In patients with familial hypercholesterolaemia, aortic stenosis is common in homozygotes, and aortic root involvement is always present despite the lower CYS than in heterozygotes. It appears to be determined by short term exposure to high cholesterol concentrations in early life. Conversely, aortic root and valve involvement are rare in heterozygotes and occur only with severe, prolonged hypercholesterolaemia, possibly accelerating age related degenerative effects.

(Heart 1998;80:583-590)

Keywords: familial hypercholesterolaemia; aortic valve disease; echocardiography

Familial hypercholesterolaemia $(\mathrm{FH})$ is characterised by dominantly inherited hypercholesterolaemia, early appearance of cutaneous and tendon xanthomata, and a predisposition to premature cardiovascular disease. Inheritance of one mutant gene causes heterozygous $\mathrm{FH}$
(1:500), while inheritance of two mutant genes gives rise to phenotypic homozygosity (1:1000 000).

Premature coronary artery disease is common in $\mathrm{FH}$, while atheromatous involvement of the aortic valve and root is almost always present in homozygotes. ${ }^{1}$ Lipid infiltration with consequent thickening of the aortic cusps is considered to be a unique feature of homozygotes and can affect the valve's mobility. ${ }^{2}$ However, atherosclerotic involvement of the aortic root is an even more common complication, rarely reported in heterozygotes, and leads to ostial stenosis and "supravalvar" aortic stenosis. Previous reports of aortic valve and root involvement in homozygous $\mathrm{FH}$ were based on cardiac catheterisation and cross sectional echocardiography. ${ }^{3-5}$ Aortography shows characteristic aortic root funnelling when the proximal ascending aorta is infiltrated by atheroma. The gradient across the aortic valve indicates the severity of its involvement, but the invasive nature of catheterisation restricts the use of this diagnostic procedure to symptomatic patients or those with clinical evidence of severe aortic stenosis. However, the increasing use of Doppler echocardiography over the past decade has made the early detection and precise assessment of aortic stenosis much easier, ${ }^{67}$ and provides an excellent tool for the screening and follow up of these patients.

To test the hypothesis that lifelong exposure to high cholesterol concentrations largely determines the magnitude of aortic valve and root disease, we studied the frequency and haemodynamic significance of valvar and supravalvar aortic stenosis in $\mathrm{FH}$ homozygotes and heterozygotes, using cross sectional and Doppler echocardiography.

\section{Methods}

PATIENTS

Eighty four consecutive patients with $\mathrm{FH}$ were studied over a one year period during 1995 to 1996. All were outpatients at the lipid clinic at Hammersmith Hospital, which most had been attending regularly for several years. All patients had normal thyroid, renal, and hepatic function and none had diabetes mellitus.

HOMOZYGOTE GROUP

This consisted of six patients (two male, four female) with a mean (SD) age of 22.8 (7.7) years (range 12 to 32 years). Pretreatment mean serum cholesterol concentration was 21.1 (4.8) $\mathrm{mmol} / \mathrm{l}$ and the geometric mean 
concentration of lipoprotein(a) ( $\mathrm{Lp}(\mathrm{a})$ ) was $24.4(2.6) \mathrm{mg} / \mathrm{dl}$. All patients except case 6 were receiving statins, while cases 3 and 4 were also on biweekly low density lipoprotein (LDL) apheresis. Case 6 was on a combination of an anion exchange resin, fibrate, and nicotinic acid. The mean serum cholesterol concentration at the time of echocardiography was 10.5 (2.0) $\mathrm{mmol} / \mathrm{l}$.

\section{HETEROZYGOTE GROUP}

This group consisted of 78 patients (49 male, 29 female) with a mean age of 52.2 (13.8) years (age range 22 to 84 years). The diagnosis was based on primary hypercholesterolaemia (> $7.5 \mathrm{mmol} / \mathrm{l}$ ) with an autosomal dominant pattern of inheritance, presence of tendon xanthomata in the patient or a first degree relative, and a family history of premature coronary artery disease. Fourteen patients had proven mutations at the LDL receptor gene locus, determined as described previously. ${ }^{8}$ At the time of examination most patients were receiving either an $\mathrm{HMG}-\mathrm{CoA}$ reductase inhibitor (statin) (43\%), an anion exchange resin (8\%), a fibrate $(5 \%)$, or combinations of these classes of drug. Five heterozygotes were also on nicotinic acid.

\section{ECHOCARDIOGRAPHY}

In all patients cross sectional Doppler (colour, pulsed, continuous) echocardiography was performed with a Toshiba SSH-160A electronic scanner with a 3.75 or $2.5 \mathrm{MHz}$ transducer (Toshiba Inc, Tokyo, Japan) and recorded on $3 / 4$ inch videotape for subsequent review.

Initially, we undertook a comprehensive echocardiographic study to obtain optimal imaging of the aortic root, ascending aorta, and aortic valve, without knowledge of the patients' clinical characteristics. For this purpose, we used a $3.75 \mathrm{MHz}$ transducer from parasternal long and short axis projections, with the transducer focus at the level of the aortic valve. For better imaging of the proximal ascending aorta, we used a higher left parasternal window in most patients, with a parallel gradual decrease of the overall gains for better delineation of the inner walls of the aortic root. From these projections and with decreased gains (approximately by $10 \mathrm{db}$ ), we measured the internal diameter of the aortic ring (annulus), the diameter at the mid-level of the sinuses of Valsalva (mid-sinus level), and the diameter at the supravalvar ring (sinotubular junction). The minimum luminal diameter between aortic valve and supravalvar level was then noted in order to document the origin of the maximum gradient. We confirmed the minimum aortic narrowing with colour Doppler superimposed on grey scale imaging to identify the maximal aliasing or turbulence region. We also used short axis projections of the aortic valve, sinuses, and ascending aorta on cine-loop format and assessed the thickness of the aortic valve by measuring the most thickened cusp at the maximally affected area.

After optimal description of the aortic root and valve anatomy and identification of the level of maximal narrowing, we employed a 2 $\mathrm{MHz}$ stand alone continuous wave Doppler transducer to measure the maximum transaortic velocity, assuming that it corresponds to the minimum aortic narrowing described. For this, all possible transducer positions were used including apical, right parasternal, high parasternal, and suprasternal positions, and the highest transaortic velocity was recorded.

For optimal assessment of the overall involvement of the aortic valve and root, we devised an aortic valve root score. Aortic valve thickening was scored as follows: 1 , normal thickness ( $\leqslant 2 \mathrm{~mm}) ; 2$, localised or nodular thickening involving one cusp; 3 , diffuse thickening $(2-4 \mathrm{~mm})$ involving one or more cusps; 4 , diffuse thickening $>4 \mathrm{~mm}$ involving one or more cusps. Valve mobility was scored as: 1, normal; 2, mildly restricted; 3, moderately restricted; 4, severely restricted (almost fixed). The aortic root was measured at mid-sinus level, evaluated subjectively for evidence of increased echogeneity/brightness, and gauged as follows: 1, normal appearance with no evidence of narrowing (diameter $>20 \mathrm{~mm}$ ); 2 , increased echogeneity but no evidence of narrowing (diameter $>20 \mathrm{~mm}$ ); 3, supravalvar narrowing (diameter $16-20 \mathrm{~mm}$ ); 4, marked supravalvar narrowing (diameter $<16 \mathrm{~mm}$ ). The aortic valve root score was calculated by summing all three scores and thus ranged from 3 (normal) to 12 (worst).

\section{LABORATORY PROCEDURES}

Blood samples were obtained after an overnight fast of 12 hours for lipid and lipoprotein analysis within three months of echocardiography. Serum cholesterol, triglyceride, and high density lipoprotein (HDL) cholesterol were assayed enzymatically by automated procedures, HDL cholesterol being assayed after preliminary precipitation of very low density lipoprotein and LDL with heparin and manganese. ${ }^{9}$ LDL cholesterol was calculated ${ }^{10}$ and $\mathrm{Lp}$ (a) was assayed using a commercial enzyme linked immunosorbent assay (Tint Elize, Biopool, Umeå, Sweden).

The "cholesterol-years" score (CYS) for assessing the lifelong exposure to hypercholesterolaemia was calculated by modifying the formula of Hoeg et $a l,{ }^{11}$ as follows: the total cholesterol concentration (mmol/l) of each patient at the time of original diagnosis was multiplied by the age of patient at diagnosis; the mean cholesterol concentration in the patient while on treatment before the introduction of statins was multiplied by the number of years of non-statin treatment; finally, the mean cholesterol concentration on statin treatment was multiplied by the number of years of statin treatment up to the time of echocardiographic examination. The sum of the pretreatment, non-statin treatment, and statin treatment cholesterol $\times$ years scores gave the total CYS. The average lifetime CYS was derived by dividing the total CYS by the current age of the patient. 
Table 1 Age, sex, and serum lipids of patients with homozygous and severe heterozygous FH at the time of diagnosis. The mean (SD) values in the remaining 75 heterozygotes are also shown

\begin{tabular}{|c|c|c|c|c|c|c|c|}
\hline \multirow[b]{2}{*}{ Patient } & \multirow[b]{2}{*}{ Age (years) } & \multirow[b]{2}{*}{$\operatorname{Sex}$} & \multirow[b]{2}{*}{ Phenotype } & \multicolumn{4}{|c|}{ At diagnosis (mmol/l) } \\
\hline & & & & $T C$ & $T G$ & $H D L-C$ & $L D L-C$ \\
\hline 1 & 28 & $\mathrm{~F}$ & Homozygous & 17.5 & 0.72 & 1.04 & 16.1 \\
\hline $2 \dagger$ & 26 & $\mathrm{~F}$ & Homozygous & 17 & 0.9 & 0.9 & 15.7 \\
\hline 3 & 12 & $\mathrm{~F}$ & Homozygous & 28.7 & 1.72 & 0.65 & 27.3 \\
\hline 4 & 26 & M & Homozygous & 24.4 & 0.7 & 0.9 & 23.2 \\
\hline 5 & 32 & $M$ & Homozygous & 22.3 & 0.9 & 0.7 & 21.2 \\
\hline 6 & 15 & $\mathrm{~F}$ & Homozygous & 17 & 1.5 & 1.3 & 15 \\
\hline 7 & 70 & $\mathrm{~F}$ & Severe heterozygous ${ }^{\star}$ & 18.1 & 1.9 & 1.2 & 16 \\
\hline 8 & 61 & $\mathrm{~F}$ & Severe heterozygous & 17.4 & 1.1 & 1 & 15.9 \\
\hline 9 & 62 & M & Severe heterozygous & 19 & 3.5 & 0.9 & 16.5 \\
\hline $10-84$ & $51.6(14)$ & $47 \mathrm{M} / 28 \mathrm{~F}$ & Heterozygous & $10.4(1.8)$ & $1.8(1.7)$ & $1.16(0.26)$ & $8.5(2.0)$ \\
\hline
\end{tabular}

HDL-C, high density lipoprotein cholesterol; LDL-C, low density lipoprotein cholesterol; TC, total cholesterol; TG, triglyceride. * $\mathrm{TC}>17 \mathrm{mmol} / 1$

†Patient No 2 was reported previously. ${ }^{13}$

STATISTICAL ANALYSIS

Values are expressed as mean (SD). Logarithmic transformation of $\mathrm{Lp}$ (a) values was performed in order to normalise its highly skewed distribution and enable calculation of the geometric mean. Differences between means were compared with unpaired Student's $t$ test. The significance of any differences in proportions was tested with the $\chi^{2}$ statistic. Spearman's rank correlation coefficients were used to assess relations between variables. Multivariate stepwise regression analysis was used to assess independence of associations. A $p$ value of $<0.05$ was considered statistically significant.

\section{Results}

HOMOZYGOTES

Tables 1 and 2 show the lipid characteristics of the six homozygous subjects, and table 3 shows the echocardiographic findings. None of the homozygotes was hypertensive or a smoker. Case 6 had undergone cardiac surgery in 1984 and Doppler information was not available at that time. Therefore in table 3, we give her peak to peak transaortic gradient obtained by cardiac catheterisation before surgery and the corresponding lipid values.

Four homozygotes (cases 1, 2, 5, and 6) had severe aortic stenosis as indicated by mean gradients of $>50 \mathrm{~mm} \mathrm{Hg}$ and a peak gradient of $130 \mathrm{~mm} \mathrm{Hg}$ in case 6 . Their mean (SD) CYS was $387(124) \mathrm{mmol} / 1 \times$ years. The aortic cusps were diffusely thickened ( 3.2 to $4.6 \mathrm{~mm}$ ), more so at the tips but without commissural fusion; their aortic valve root scores ranged from 10 to 11. Figure 1 shows the histological findings of the excised aortic valve of case 2 . There was focal deposition of calcium, fibrosis, and chronic inflammatory cells. Lipid stains showed central cholesterol clefts and oxidised lipid both within macrophages and extracellularly. None of the patients had a bicuspid aortic valve. The anterior mitral leaflet was also thickened to a lesser degree in cases 2,5 , and 6 , but the overall valve mobility was normal.

Echocardiographic evidence of supravalvar narrowing was obtained in four homozygotes (cases 1, 2, 5, and 6) in whom there was highly echogenic material encircling the aortic root and mainly arising from the sinuses of Valsalva, with a considerable reduction of the diameter at mid-sinus level (fig 2A). Cases 2 and 6 underwent cardiac catheterisation, which confirmed the presence of supravalvar atheroma by the funnelled appearance of the ascending aorta (fig 2B). The gradient in both cases was transvalvar

In cases 3 and 4 the aortic root was highly echogenic but less thickened than in the other homozygotes and the aortic cusps were normal. The diameter at mid-sinus level was the same as that of the aortic annulus; this is considered abnormal since a mean increase of $12.5 \%$ is expected at mid-sinus level compared with the annulus diameter. ${ }^{12}$ These findings, in association with the accelerated velocity along the ascending aorta, were suggestive of supravalvar aortic atheromatous involvement, although this was relatively mild, with an aortic valve root score of 5 in both cases.

None of the homozygotes had resting left ventricular wall motion abnormalities, which

Table 2 Age treatment started, serum lipids on treatment, and cholesterol-years score in patients with homozygous (Nos 1-6) and severe heterozygous (Nos 7-9) familial hypercholesterolaemia. The mean (SD) values in the remaining 75 heterozygotes are also shown

\begin{tabular}{|c|c|c|c|c|c|}
\hline \multirow[b]{2}{*}{ Patient } & \multirow[b]{2}{*}{ Age treatment started (years) } & \multicolumn{3}{|c|}{ At echocardiography } & \multirow[b]{2}{*}{ CYS (mmol/l $\times$ years $)$} \\
\hline & & $T C(\mathrm{mmol} / \mathrm{l})$ & $L D L-C(\mathrm{mmol} / \mathrm{l})$ & $L p(a)(m g / d l)$ & \\
\hline 1 & 9 & 12.8 & 11.2 & 60 & 465 \\
\hline 2 & 16 & 11.5 & 9.9 & 23 & 400 \\
\hline 3 & 3 & 8 & 7.1 & 63 & 194 \\
\hline 4 & 2 & 8 & 6.8 & 35 & 480 \\
\hline 5 & 12 & 11.3 & 9.6 & 5 & 475 \\
\hline 6 & 7 & 10.3 & 8.3 & 14 & 207 \\
\hline 7 & 63 & 6.7 & 4.8 & 49 & 1217 \\
\hline 8 & 43 & 8.8 & 7 & 32 & 972 \\
\hline 9 & 40 & 10.5 & 8.2 & 5 & 990 \\
\hline $10-84$ & $41.6(13.3)$ & $6.8(1.7)$ & $4.9(1.6)$ & $21.5(4.1)^{\star}$ & $501.4(136)$ \\
\hline
\end{tabular}

CYS, cholesterol-years score; LDL-C, low density lipoprotein cholesterol; Lp(a), lipoprotein(a); TC, total cholesterol. ${ }^{\star}$ Geometric mean. 
Table 3 Echocardiographic findings in patients with homozygous (Nos 1-6) and severe heterozygous (Nos 7-9) familial hypercholesterolaemia, and mean (SD) values in the remaining 75 heterozygotes

\begin{tabular}{|c|c|c|c|c|c|c|c|c|c|c|}
\hline Patient & $\begin{array}{l}\text { Supravalvar } \\
\text { atheroma } \\
\text { present }\end{array}$ & $\begin{array}{l}\text { Annulus } \\
\text { diameter } \\
(\mathrm{mm})\end{array}$ & $\begin{array}{l}\text { Mid-sinus } \\
\text { diameter } \\
(\mathrm{mm})\end{array}$ & $\begin{array}{l}\text { Diameter of } \\
\text { supravalvar } \\
\text { ring (mm) }\end{array}$ & $\begin{array}{l}\text { Maximum } \\
\text { thickness of aortic } \\
\text { cusps (mm) }\end{array}$ & $\begin{array}{l}\text { Mobility of aortic } \\
\text { cups }\end{array}$ & $\begin{array}{l}\operatorname{Vmax} \\
(\mathrm{m} / \mathrm{s})\end{array}$ & $\begin{array}{l}\text { Peak } \\
\text { gradient } \\
\text { (mm Hg) }\end{array}$ & $\begin{array}{l}\text { Mean } \\
\text { gradient } \\
(\mathrm{mm} \mathrm{Hg})\end{array}$ & $A V R S$ \\
\hline 1 & Yes & 17 & 14.4 & 17.2 & 3.4 & Mildly restricted & 4.4 & 77 & 52 & 10 \\
\hline 2 & Yes & 20 & 14.5 & 16.5 & 4.6 & Mildly restricted & 6 & 147 & 92 & 11 \\
\hline 3 & Possibly & 17 & 17 & 16.1 & $<2$ & Normal & 2.5 & 25 & 13 & 5 \\
\hline 4 & Possibly & 19 & 19 & $\star$ & $<2$ & Normal & 2.9 & 33 & 19 & 5 \\
\hline 5 & Yes & 18 & 15 & 15.5 & 3.2 & Mildly restricted & 4.7 & 88 & 51 & 10 \\
\hline 6 & Yes & 17 & 15 & 16 & 3.2 & Mildly restricted & - & $130 \dagger$ & - & 10 \\
\hline 7 & Uncertain & 18.1 & 19.8 & 18.6 & 3.6 & Severely restricted & 4.9 & 98 & 63 & 9 \\
\hline 8 & Yes & 17.4 & 16.1 & 18.2 & 3.8 & Mildly restricted & 5.4 & 118 & 74 & 9 \\
\hline 9 & No & 25 & 30 & 23 & 3.3 & Normal & 1.5 & 9 & 5 & 5 \\
\hline $10-84$ & $\begin{array}{l}6 \text { with bright } \\
\text { aortic root }\end{array}$ & $22.4(2.5)$ & $31.5(4.2)$ & $26.5(3.8)$ & $2.7(0.5) \ddagger$ & Normal§ & $1.3(0.3)$ & $6.7(3.4)$ & $3.8(2.3)$ & $3.5(0.87)$ \\
\hline
\end{tabular}

Vmax, peak transaortic velocity.

^No clear visualisation of supravalvar ring; tpeak to peak gradient on cardiac catheterisation; ¥in the 14 heterozygotes with thickened aortic valve; \only in one case mildly restricted.

excluded previous myocardial infarction. Table 4 shows the coronary anatomy, the condition of the coronary sinuses, and the type of cardiac surgery undertaken in three homozygotes (cases 2, 5, and 6). In all cases the right coronary ostium was narrowed and in case 5 both ostia were stenosed. The distal coronary arteries were free from significant disease with the exception of case 2 , where there was a $60 \%$ stenosis at the middle third of the left anterior
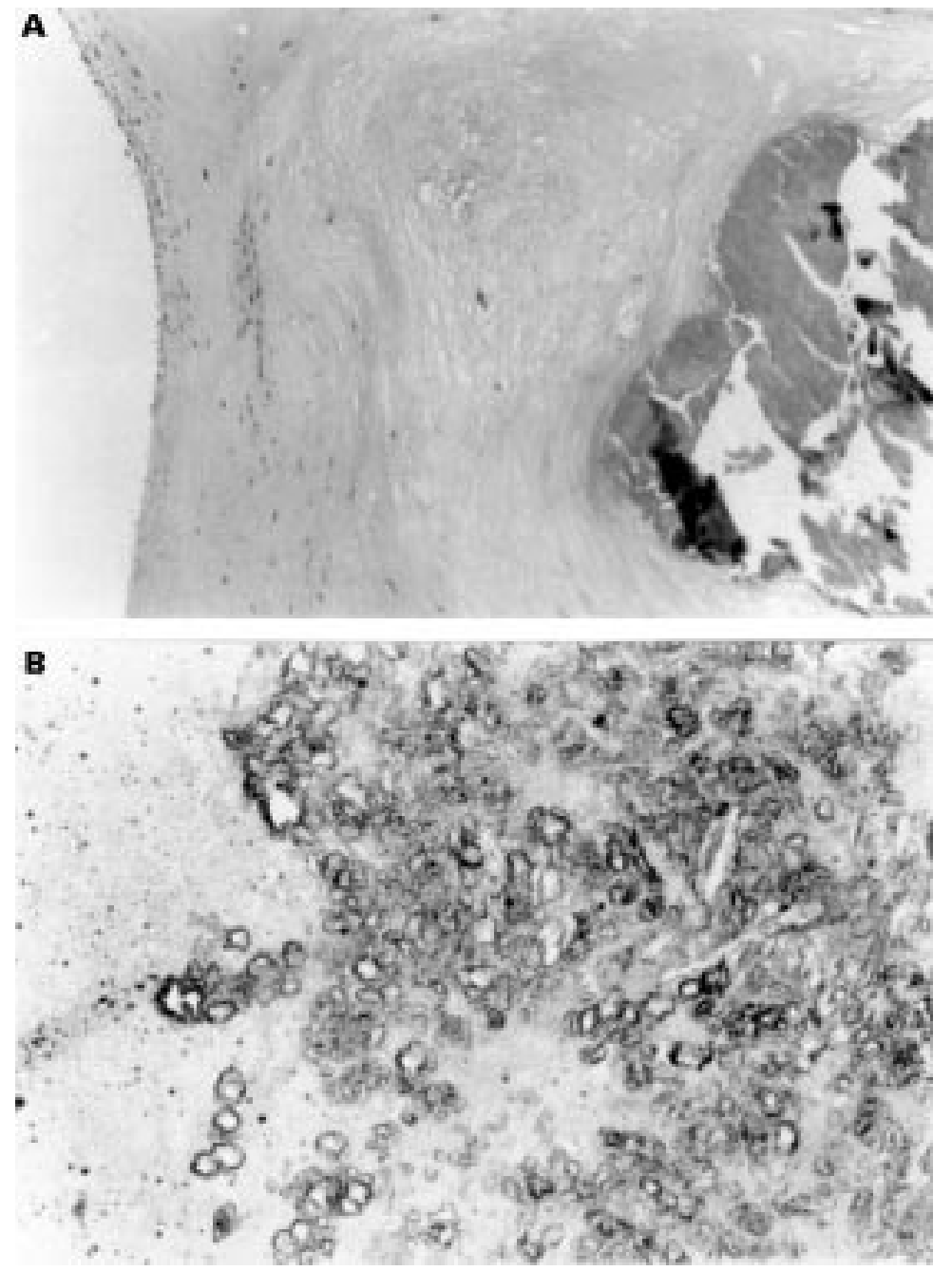

Figure 1 (A) Section of the resected valve showing fibrosis (left), cholesterol clefts (centre), and nodular calcification (right) ( $\times 42)$. (B) Higher power view of the valve stained with oil red $O$ showing insoluble lipid (ceroid) and cholesterol clefts $(\times 210)$. (By kind permission of Dr D Parums.) descending coronary artery. Cases 2 and 6 underwent successful aortic root reconstruction, aortic valve replacement, and coronary artery bypass grafting. Case 5 underwent coronary artery bypass grafting alone.

\section{HETEROZYGOTES}

Serum lipids and echocardiographic findings in three heterozygotes (cases 7, 8, and 9) with severe hypercholesterolaemia (cholesterol at original diagnosis $>17 \mathrm{mmol} / 1$, total CYS $>900 \mathrm{mmol} / 1 \times$ years), and the mean values of the remaining 75 heterozygotes are presented in tables 1,2 , and 3 . Nine $(11.5 \%)$ were hypertensive and seven (9\%) were smokers.

The mean CYS in all heterozygotes was 523 (175) $\mathrm{mmol} / \mathrm{l} \times$ years. Cases 7 and 8 had severe aortic stenosis, while case 9 had diffuse thickening of the non-coronary cusp $(3.3 \mathrm{~mm})$ without evidence of stenosis. Both the heterozygotes with severe aortic stenosis underwent cardiac catheterisation. In case 7 , the aortic valve and root were heavily calcified and the left descending coronary artery was blocked proximally. In case 8 , the aortic valve was diffusely thickened $(3.8 \mathrm{~mm})$ and the root had a funnelled appearance, typical of supravalvar narrowing. There was an $80 \%$ stenosis of the left descending coronary artery and the right ostium was blocked. The aortic valve root score ranged from 5 to 9 in these three patients.

Of the remaining 75 heterozygotes, only one had mild aortic stenosis (mean gradient $18 \mathrm{~mm}$ $\mathrm{Hg}$ ). In this patient the right and non-coronary cusps had diffuse thickening $(3.7 \mathrm{~mm})$ and their mobility was slightly restricted. In addition, the aortic root was highly echogenic but without supravalvar narrowing. Among the others, there was increased echogeneity of the aortic root in six patients, without supravalvar narrowing (mid-sinus diameter $>20 \mathrm{~mm}$ ). Sixteen patients had resting left ventricular akinesis on the echocardiographic study, implying previous transmural myocardial infarction. The mean aortic valve root score of these 75 patients was 3.5 (table 3 ).

Table 5 shows the correlations between maximum transaortic velocity, peak gradient, and mean gradient across the aortic valve with age and serum lipids. Multiple regression analysis was applied to assess the independence of association between mean aortic gradient and the variables in table 5. In a stepwise 

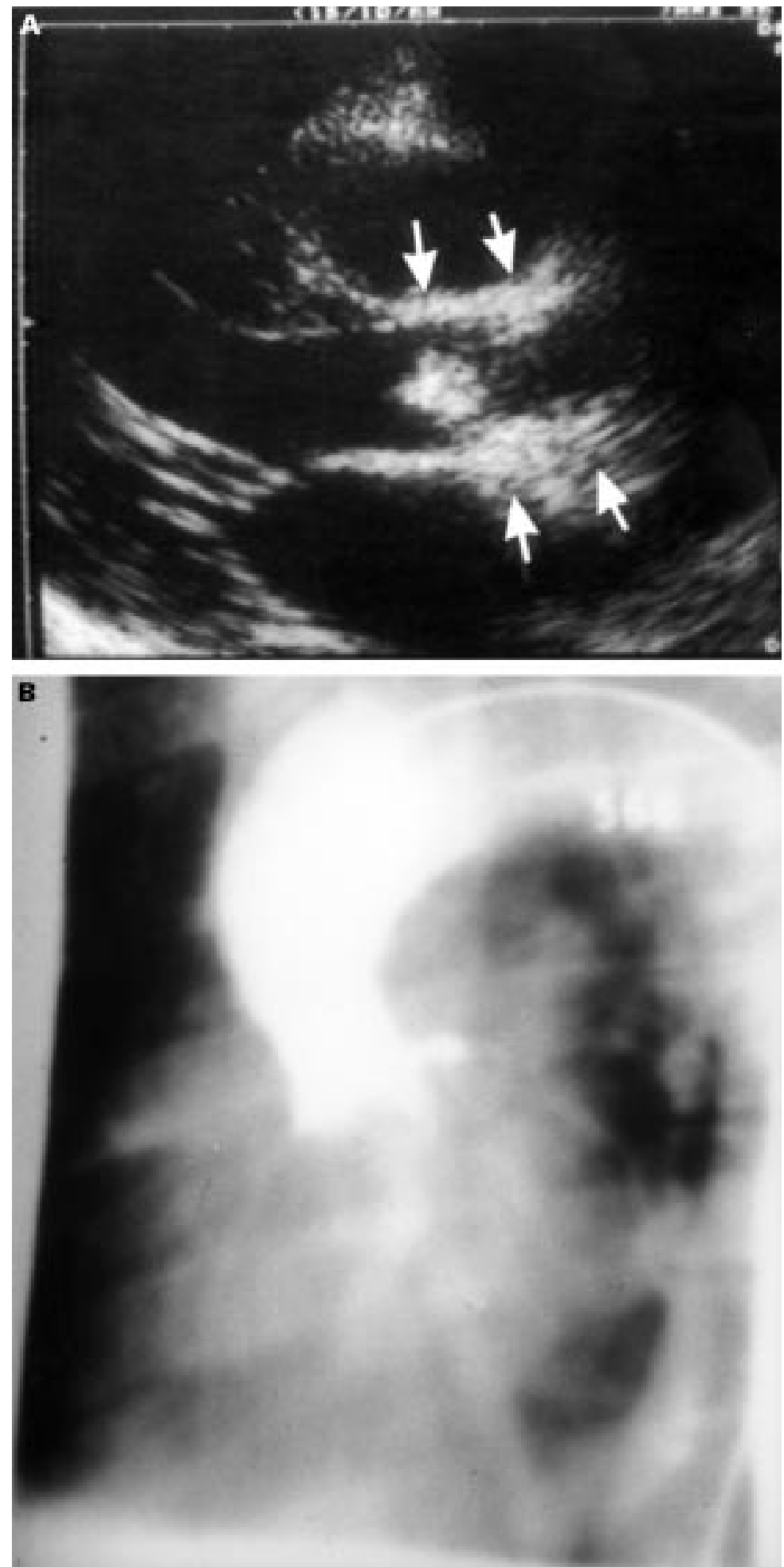

Figure 2 (A) Parasternal long axis view showing a highly echogenic aortic root (arrows) and thickening of the aortic valve. The focus zone of the ultrasound beam is at the anterior aortic wall. (B) Aortography of the same patient showing the characteristic funnelling of the proximal ascending aorta.

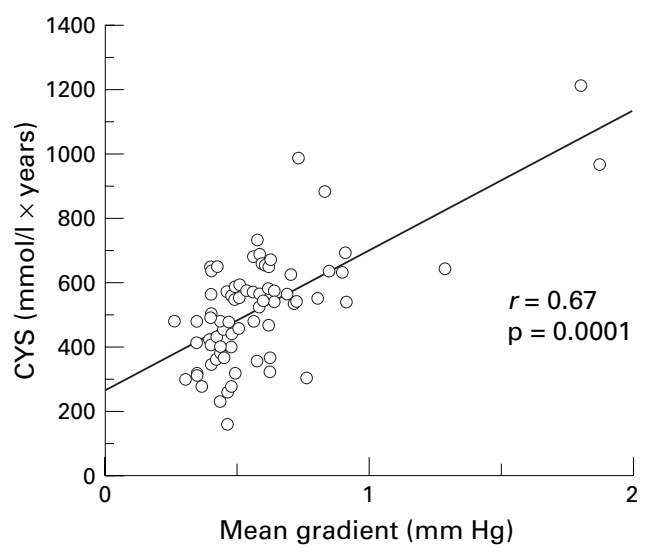

Figure 3 Correlation between mean gradient across the aortic valve (after logarithmic transformation) and

cholesterol-years score (CYS) in patients with heterozygous familial hypercholesterolaemia $(n=78)$.

Seventeen heterozygotes (22\%) had thickening of aortic cusps, but only in two $(2.6 \%)$ was this associated with severe aortic stenosis and in one with mild aortic stenosis. Five of the heterozygotes studied were over the age of 70 years, and of these three had localised aortic valve thickening but none had aortic stenosis. In an effort to minimise the contribution from senile degenerative aortic valve disease, we compared the serum lipids in the 73 heterozygotes aged $\leqslant 70$ years according to the presence of aortic valve thickening. The heterozygotes with thickened aortic valves were older and had significantly higher total and LDL cholesterol at diagnosis and had higher total and average CYS/year, but there was no difference in serum lipids or $\operatorname{Lp}(\mathrm{a})$ concentrations at the time of echocardiography (table 6). There was also a significant positive correlation between aortic valve root score and total CYS in the heterozygotes aged $\leqslant 70$ years (fig 4 ).

\section{Discussion}

In this study we found paradoxically that homozygote patients with $\mathrm{FH}$ get severe aortic root and valve involvement at lower CYS scores than heterozygotes. This suggests that aggregates of LDL at the high concentrations found in homozygotes, but seldom in heterozygotes, are responsible, rather than the lifetime elevation of cholesterol levels found in the heterozygous group.

Histologically the aortic valve and root lesions consist of foam cells, cholesterol clefts, and fibrocalcific deposits. The presence of intracellular lipid and cholesterol clefts within the cuspal tissues is unique to homozygous $\mathrm{FH}$ and differentiates these lesions from other forms of aortic stenosis. Despite the significant thickening of the aortic cusps, there was no commissural fusion and good overall cusp mobility, though there was incomplete opening caused by atheromatous accumulation in the sinuses of Valsalva. This mechanism of aortic stenosis explains the clinical paradox of a well preserved aortic closure sound. Our findings are consistent with previous reports which ascribe the aortic stenosis in homozygotes to a 
Table 4 Coronary anatomy, condition of sinuses of Valsalva, and type of cardiac surgery in three homozygotes

\begin{tabular}{|c|c|c|c|c|}
\hline Patient & Coronary anatomy & $\begin{array}{l}\text { Condition of sinuses of } \\
\text { Valsalva }\end{array}$ & Type of operation & $\begin{array}{l}\text { Age at operation } \\
\text { (years) }\end{array}$ \\
\hline 2 & $\begin{array}{l}\text { Right ostial } \\
\text { occlusion, LAD } \\
\text { stenosis }\end{array}$ & $\begin{array}{l}\text { Right coronary sinus } \\
\text { obliterated }\end{array}$ & $\begin{array}{l}\text { ARR (pericardial patch), } \\
\text { AVR, } 2 \text { grafts }\end{array}$ & 26 \\
\hline 5 & $\begin{array}{l}\text { Right and left ostial } \\
\text { stenosis }\end{array}$ & All sinuses infiltrated & 4 grafts $\star$ & 21 \\
\hline 6 & $\begin{array}{l}\text { Right ostial } \\
\text { occlusion }\end{array}$ & $\begin{array}{l}\text { Right and non-coronary } \\
\text { sinuses obliterated }\end{array}$ & $\begin{array}{l}\text { ARR (pericardial patch), } \\
\text { AVR, } 1 \text { graft }\end{array}$ & 15 \\
\hline
\end{tabular}

ARR, aortic root reconstruction; AVR, aortic valve replacement; LAD, left anterior descending coronary artery.

*The coronary artery bypass graft was performed in 1985 when the peak to peak gradient across the aortic valve was $20 \mathrm{~mm} \mathrm{Hg}$.

Table 5 Spearman's correlation coefficients between maximum transaortic velocity, peak gradient, mean gradient with age, lipids, and cholesterol-years score in all heterozygotes ( $n$ $=78$ )

\begin{tabular}{llll}
\hline Variable & Vmax & Peak gradient & Mean gradient \\
\hline Age & $r=0.29 ; \mathrm{p}=0.01$ & $r=0.22 ; \mathrm{NS}$ & $r=0.21 ; \mathrm{NS}$ \\
TC (d) & $r=0.52 ; \mathrm{p}=0.0001$ & $r=0.51 ; \mathrm{p}=0.0001$ & $r=0.51 ; \mathrm{p}=0.0001$ \\
TG (d) & $r=0.03 ; \mathrm{NS}$ & $r=0.05 ; \mathrm{NS}$ & $r=0.05 ; \mathrm{NS}$ \\
HDL-C (d) & $r=0.01 ; \mathrm{NS}$ & $r=0.08 ; \mathrm{NS}$ & $r=0.09 ; \mathrm{NS}$ \\
LDL-C (d) & $r=0.56 ; \mathrm{p}=0.0001$ & $r=0.56 ; \mathrm{p}=0.0001$ & $r=0.55 ; \mathrm{p}=0.0001$ \\
TC (e) & $r=0.07 ; \mathrm{NS}$ & $r=0.08 ; \mathrm{NS}$ & $r=0.09 ; \mathrm{NS}$ \\
LDL-C (e) & $r=0.09 ; \mathrm{NS}$ & $r=0.01 ; \mathrm{NS}$ & $r=0.11 ; \mathrm{NS}$ \\
Lp(a) (e) & $r=0.07 ; \mathrm{NS}$ & $r=0.07 ; \mathrm{NS}$ & $r=0.08 ; \mathrm{NS}$ \\
CYS & $r=0.53 ; \mathrm{p}=0.0001$ & $r=0.59 ; \mathrm{p}=0.0001$ & $r=0.58 ; \mathrm{p}=0.0001$ \\
\hline
\end{tabular}

CYS, cholesterol-years score; HDL-C, high density lipoprotein cholesterol; LDL-C, low density lipoprotein cholesterol; Lp(a), lipoprotein(a); TC, total cholesterol; TG, triglyceride; Vmax, maximum transaortic velocity.

*After logarithmic transformation.

(d), at initial diagnosis; (e), at the time of echocardiography.

valvar gradient secondary to supravalvar narrowing, ${ }^{313}$ although there are some cases where the gradient was predominantly supravalvar, apparently owing to gross narrowing at the sinotubular junction. ${ }^{14}$ Interestingly, although the aortic valve appeared normal in two homozygotes, the ascending aorta was highly echogenic with mild narrowing at mid-sinus level suggestive of supravalvar aortic atheroma. It is possible that the absence of aortic valve involvement and the relatively mild aortic root disease in those two patients is a result of the early introduction of lipid lowering treatment ( $\leqslant 3$ years of age), consisting initially of statins and later the combination of statins with LDL apheresis.

Regression of coronary atherosclerosis has been reported with LDL apheresis in homozygotes $^{1516}$ and consequently one can speculate that a similar beneficial effect could be expected for the aortic valve and root involvement. ${ }^{17}$ In homozygotes the arrest or regression of aortic root involvement should be the main therapeutic aim, since early fatal coronary events are usually related to ostial occlusion secondary to lipid deposition in the sinuses of Valsalva. However, delayed introduc-

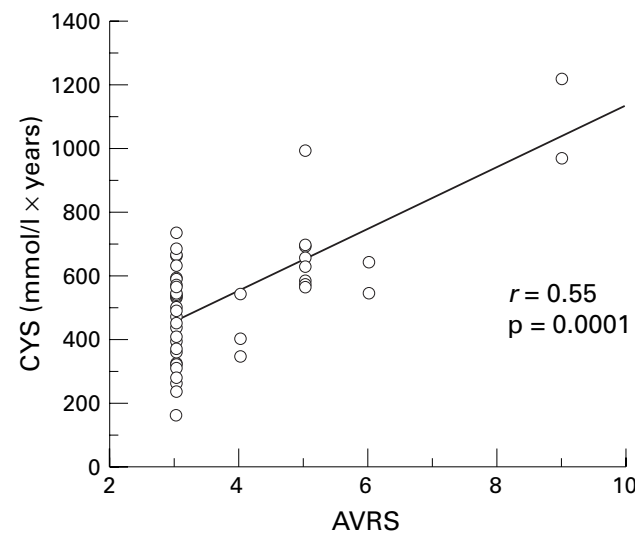

Figure 4 Correlation between cholesterol-years score (CYS) and aortic valve root score (AVRS) in heterozygotes for familial hypercholesterolaemia aged $\leqslant 70$ years.

tion of aggressive lipid lowering treatment carries the theoretical risk of worsening the valvar aortic stenosis by converting the lipid rich aortic cusps into fibrotic and more rigid cusps, since the mobilisation and removal of cholesterol may paradoxically accelerate fibrosis, as has been shown in the coronary arteries of an FH patient. ${ }^{18}$ This underlines the need to start treatment at an early stage.

The anterior mitral leaflet showed mild generalised thickening in three homozygotes (cases 2,5 , and 6), probably owing to lipid infiltration, but no evidence of valvar dysfunction. However, a 9 year old homozygote has been reported with mitral regurgitation caused by lipid infiltration of the mitral leaflets along with marked fibrosis and atrophy of the papillary muscles. ${ }^{19}$

This is the first study to report a positive correlation between the mean transaortic gradient, severity of aortic valve root involvement, and CYS in heterozygotes with familial hypercholesterolaemia. These associations suggest that lifelong exposure to high cholesterol concentrations largely determines the severity of aortic stenosis in this group and can result in combined involvement of the aortic valve and root, which is manifested by some degree of aortic valve thickening and increased echogeneity of aortic root. However, severe root involvement is rare in heterozygous $\mathrm{FH}$, in contrast with homozygous $\mathrm{FH}$.

We analysed separately the lipid and echocardiographic findings in the three heterozygotes with the most marked hypercholesterolaemia (initial cholesterol concentrations $>17$ $\mathrm{mmol} / \mathrm{l}, \mathrm{CYS}>900 \mathrm{mmol} / 1 \times$ years), two of whom had severe aortic stenosis. Case 8 had all

Table 6 Serum lipids and lipoproteins, cholesterol-years score, and average cholesterol-years score in 73 heterozygotes for familial hypercholesterolaemia aged $\leqslant 70$ years according to the presence of aortic valve thickening

\begin{tabular}{|c|c|c|c|c|c|c|c|c|c|c|}
\hline \multirow[b]{2}{*}{$\begin{array}{l}\text { Thickened } \\
\text { aortic valve }\end{array}$} & \multirow[b]{2}{*}{ Age (years) } & \multicolumn{4}{|c|}{ Lipids at diagnosis } & \multicolumn{3}{|c|}{ Lipids at echocardiography } & \multirow[b]{2}{*}{ CYS } & \multirow[b]{2}{*}{$\begin{array}{l}\text { Average } \\
\text { CYSlyear }\end{array}$} \\
\hline & & TC (mmolll) & $T G(\mathrm{mmol} / \mathrm{l})$ & $\begin{array}{l}H D L-C \\
(\mathrm{mmol} / \mathrm{l})\end{array}$ & $\begin{array}{l}L D L-C \\
(\mathrm{mmol} / \mathrm{l})\end{array}$ & $\begin{array}{l}\text { TC } \\
(\mathrm{mmol} / \mathrm{l})\end{array}$ & $\begin{array}{l}L D L-C \\
(\mathrm{mmol} / \mathrm{l})\end{array}$ & $\begin{array}{l}L p(a) \\
(m g / d l)\end{array}$ & & \\
\hline Yes $(n=14)$ & $58(9.5)$ & $12.9(3.3)$ & $1.9(0.76)$ & $1.1(0.29)$ & $11.6(3.6)$ & $7.4(2.4)$ & $5.5(2.2)$ & $37.4(2.9)^{\star}$ & $692(218)$ & $12.2(12.7)$ \\
\hline No $(\mathrm{n}=59)$ & $48.5(12.2)$ & $10.3(1.8)$ & $1.9(1.8)$ & $1.2(0.26)$ & $8.3(1.9)$ & $6.7(1.6)$ & $4.8(1.5)$ & $22.4(3.9)^{\star}$ & $467(129)$ & $9.8(1.7)$ \\
\hline p Value & 0.006 & 0.0002 & NS & NS & 0.0004 & NS & NS & NS & 0.0001 & 0.0001 \\
\hline
\end{tabular}

Values are mean (SD); CYS, cholesterol-years score; HDL-C, high density lipoprotein cholesterol; LDL-C, low density lipoprotein cholesterol; Lp(a), lipoprotein(a); TC, total cholesterol; TG, triglyceride. ${ }^{\star}$ Geometric mean. 
the characteristic features of valvar aortic stenosis secondary mainly to supravalvar narrowing which prevented the normal cusp opening. Case 7 was older (70 years), the aortic valve and root were markedly calcified, the aortic cusps had little mobility, and there was no significant narrowing at mid-sinus level, nor was there the characteristic funnelling of the aortic root on aortogram. On the basis of these findings it is unclear whether the involvement of aortic valve and root in this patient was the result of lipid infiltration followed by severe calcification or whether it was caused by degenerative aortic valve disease, or a combination of both. The third heterozygote (case 9), despite the early development of coronary artery disease (coronary artery bypass graft at 42 years, redone at 57 years), showed only mild diffuse thickening of the non-coronary aortic cusp without aortic stenosis or supravalvar narrowing. Of the remaining 75 heterozygotes, one had mild aortic stenosis without supravalvar narrowing, but the remainder were normal.

To shed further light on the mechanism of aortic valve thickening in heterozygotes we subdivided them according to the presence or absence of pathological valve thickening. Heterozygotes aged $>70$ years were excluded since it is known that age contributes to the degenerative thickening of aortic valve in the general population. ${ }^{20}$ Age, cholesterol, and LDL cholesterol at diagnosis and the CYS were the main predictors of aortic valve thickening. $L p(a)$ did not differ significantly between the subgroups, although there was a trend for higher levels in the heterozygotes with thickened aortic cusps. A recent study showed that $\mathrm{Lp}$ (a) was closely related to aortic valve sclerosis in a rural Japanese population, ${ }^{21}$ and the authors postulated that the high affinity of $\mathrm{Lp}(\mathrm{a})$ for glycosaminoglycans enhances the accumulation of $L p(a)$ in the connective tissue of aortic cusps. The absence of this association in our population presumably reflects differences in patient selection or treatment. To minimise the confounding effect of age further, we calculated the average CYS by dividing the CYS by age. This was significantly higher in the heterozygotes with aortic valve thickening, supporting our hypothesis that lifelong exposure to high cholesterol levels represents the main risk factor for the thickening of aortic cusps in this situation, possibly by accelerating age related degenerative aortic valve lesions. A recent study ${ }^{22}$ reinforces our hypothesis, suggesting that hypercholesterolaemia may be an aetiological factor in the development of aortic stenosis.

We conclude that aortic stenosis is very common in homozygotes, and aortic root involvement is always present. It appears that in homozygotes it is the exposure to a very high LDL cholesterol concentration rather than the lifelong cholesterol burden that determines aortic valve and root involvement. Early initiation of treatment slows the rate of progression, not only of the coronary atherosclerosis but of the aortic valve and root involvement. In contrast, aortic valve and root involvement are rare in heterozygotes and occur only with severe and prolonged hypercholesterolaemiathat is, when the total CYS is $>900 \mathrm{mmol} / 1 \times$ years. The occurrence of similar lesions in homozygotes with a CYS only half as high suggests that at very high concentrations, seen only in homozygotes, LDL may undergo spontaneous aggregation when subjected to turbulent flow during systole. Aggregation can be induced in vitro by vortexing concentrated LDL, and such aggregates are avidly taken up by scavenger receptors on monocyte macrophages ${ }^{23}$ and are thus potentially atherogenic. Although speculative, this proposal provides a possible explanation for the different distribution and much greater severity of aortic atherosclerosis in homozygotes compared with heterozygotes.

1 Haitas B, Baker SG, Meyer TE, et al. Natural history and cardiac manifestations of homozygous familial hyperchocardiac manifestations of homozygous
lesterolaemia. $O \mathcal{M}$ Med 1990;76:731-40.

2 Roberts WC, Ferrans VJ, Levy RI, et al. Cardiovascular pathology in hyperlipoproteinemia. Anatomic observations in 42 necropsy patients with normal or abnormal serum lipoprotein patterns. Am f Cardiol 1973;31:557-70.

3 Ribeiro P, Shapiro LM, Gonzalez A, et al. Cross sectional echocardiographic assessment of the aortic root and coronary ostial stenosis in familial hypercholesterolaemia. $\mathrm{Br}$ Heart F 1983;50:432-7.

4 Allen JM, Thompson GR, Myant NB, et al. Cardiovascular complications of homozygous familial hypercholesterolaemia. Br Heart $\mathcal{F}$ 1980;44:361-8.

5 Beppu S, Minura Y, Sakakibara H, et al. Supravalvular aortic stenosis and coronary ostial stenosis in familial hypercholesterolemia: two-dimensional echocardiographic assessment. Circulation 1983;67:878-84.

6 Berger M, Berdoff RL, Gallerstein PE, et al. Evaluation of aortic stenosis by continuous wave Doppler ultrasound. $\mathcal{f}$ Am Coll Cardiol 1984;3:150-6.

7 Hatle L, Angelsen BA, Tromsdal A. Non-invasive assessment of aortic stenosis by Doppler ultrasound. Br Heart $\mathcal{F}$ 1980;43:284-92.

8 Webb JC, Sun X, McCarthy SM, et al. Characterization of mutations in the low density lipoprotein (LDL)-receptor gene in patients with homozygous familial hypercholesteroemia, and frequency of these mutations in familial hypercholesterolaemia patients in the United Kingdom. F Lipid Res 1996;37:368-81.

9 Warnick GR, Albers JJ. A comprehensive evaluation of the heparin-manganese precipitation procedure for estimating high density lipoprotein cholesterol. F Lipid Res 1978;19: $65-76$.

10 Friedewald WT, Levy RI, Fredrickson DS. Estimation of the concentration of low-density lipoprotein cholesterol in plasma, without use of the preparative ultracentrifuge. Clin Chem 1972;18:499-502.

11 Hoeg JM, Feuerstein IM, Tucker EE. Detection and quantitation of calcific atherosclerosis by ultrafast computed tomography in children and young adults with homozygous familial hypercholesterolemia. Arterioscler Thromb 1994;14: 1066-74.

2 Weyman AE, Caldwell RL, Hurwitz RA, et al. Crosssectional echocardiographic characterization of aortic obstruction. 1. Supravalvular aortic stenosis and aortic hypoplasia. Circulation 1978;57:491-7.

13 Rallidis L, Nihoyannopoulos P, Thompson GR. Aortic stenosis in homozygous familial hypercholesterolaemia. Heart 1996;76:84-5.

14 Wennevold A, Jacobsen JG. Acquired supravalvular aortic stenosis in familial hypercholesterolemia. A hemodynamic and angiocardiographic study. Am $\mathcal{F}$ Med 1971;50:823-7.

15 Thompson GR, Barbir M, Okabayashi K, et al. Plasmapheresis in familial hypercholesterolemia. Arteriosclerosis 1989; 9(suppl):I-152-7.

16 Tatami R, Inoue $\mathrm{N}$, Itoh $\mathrm{H}$, et al. Regression of coronary atherosclerosis by combined LDL-apheresis and lipidowering drug therapy in patients with familial hypercholesterolemia: a multicenter study. The LARS Investigators. Atherosclerosis 1992;95:1-13.

17 Keller C, Schmitz H, Theisen K, et al. Regression of valvular aortic stenosis due to homozygous familial hypercholesterolemia following plasmapheresis. Klin Wochenschr 1986; 64:338-41.

18 Koga N, Iwata Y. Pathological and angiographic regression of coronary atherosclerosis by LDL-apheresis in a patient 9-21.

19 Buja LM, Kovanen PT, Bilheimer DW. Cellular pathology of homozygous familial hypercholesterolemia. Am f Pathol 1979;97:327-57. 
20 Lindroos M, Kupari M, Heikkila J, et al. Prevalence of aortic valve abnormalities in the elderly: an echocardiographic study of a random population sample. $7 \mathrm{Am}$ Coll Cardio $1993 ; 21: 1220-5$.

21 Gotoh $\mathrm{T}$, Kuroda $\mathrm{T}$, Yamasawa $\mathrm{M}$, et al. Correlation between lipoprotein(a) and aortic valve sclerosis assessed by echocardiography (the JMS Cardiac Echo and Cohor Study). Am $\mathcal{F}$ Cardiol 1995;76:928-32.
22 Wilmshurst PT, Stevenson RN, Griffiths $\mathrm{H}$, et al. A case-control investigation of the relation between hyperlipidaemia and calcific aortic valve stenosis. Heart 1997;78: 475-9.

23 Khoo JC, Miller E, McLoughlin P, et al. Enhanced macrophage uptake of low density lipoprotein after self-aggregation. Arteriosclerosis 1988;8:348-58.

\section{IMAGES IN CARDIOLOGY}

\section{"Steam iron" appearance of chronic thoracic aortic dissection on angiography}

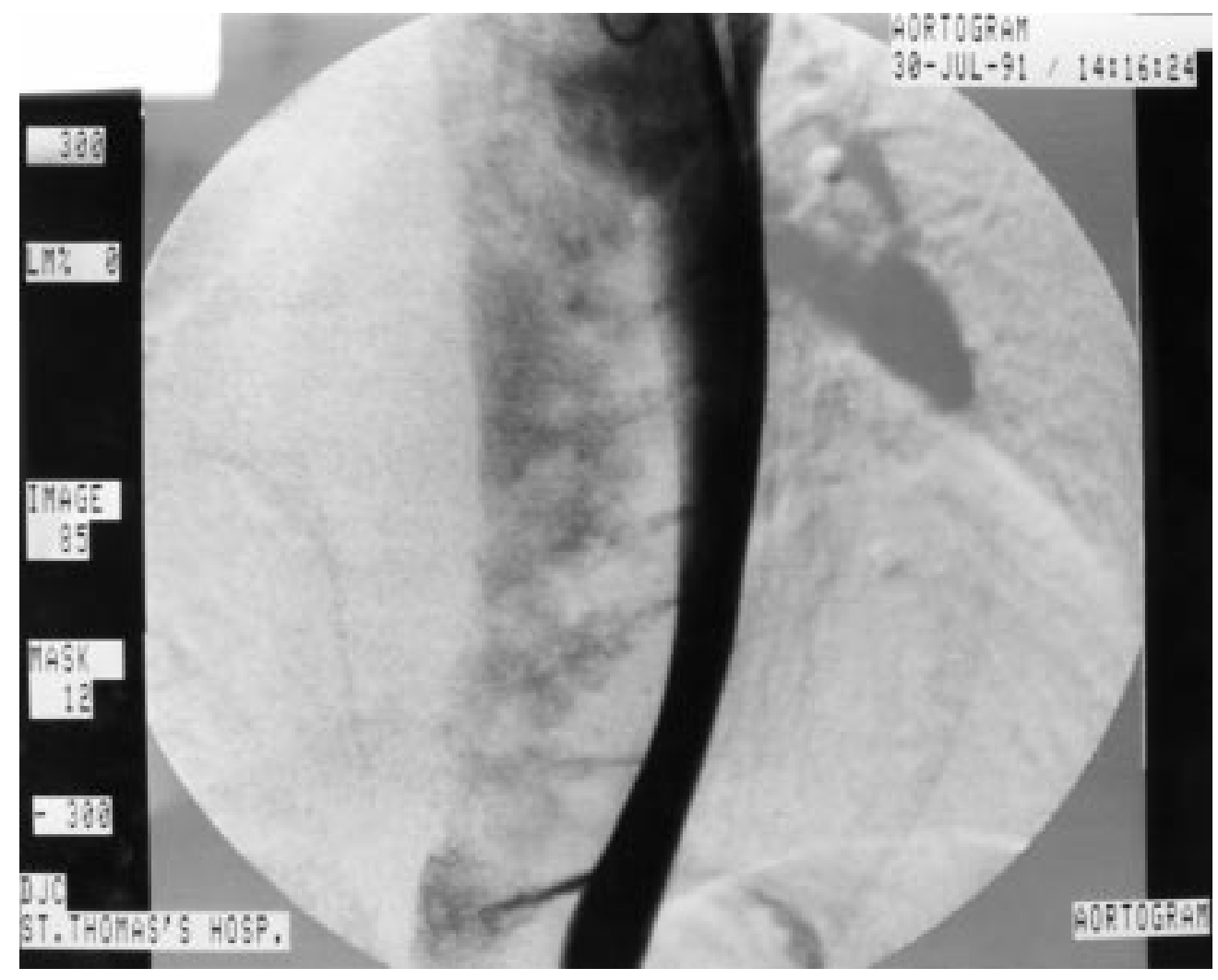

A 42 year old man was referred for investigation of an abnormal chest $x$ ray that showed profound widening of the mediastinum suggestive of a large thoracic aneurysm. At the age of 35 years he had collapsed while at work. At the time no specific cause had been found. He was otherwise fit and well. Thoracic computed tomography had showed dilatation of the aorta extending from the arch to the level of the renal arteries but did not confirm dissection. Transthoracic echocardiography had suggested an intimal flap within the descending aorta. Transoesophageal echocardiography was not routinely available at that time.
The image shows a contrast angiogram of the descending aorta revealing extensive dissection with compression of the true lumen by a large false lumen. The true lumen communicates with the false lumen through a number of stripped off intercostal arteries giving a series of jets akin to those seen when using a steam iron.

Following discussion with cardiothoracic surgeons it was decided to treat the patient conservatively.

MICHAEL CELINSKI CLIVE S LAWSON 